\section{Reactivation of Ocular \\ Toxoplasmosis in Non-Hispanic Persons, Misiones Province, Argentina}

\author{
Marcelo Rudzinski, Marina Khoury, \\ Cristobal Couto, Daniel Ajzenberg
}

Author affiliations: Universidad Católica de las Misiones, Misiones, Argentina (M. Rudzinski); Instituto de Investigaciones Médicas Alfredo Lanari, Buenos Aires, Argentina (M. Khoury); Hospital de Clínicas José de San Martin, Buenos Aires (C. Couto); Université de Limoges, Limoges, France (D. Ajzenberg)

DOI: http://dx.doi.org/10.3201/eid2205.150025

To the Editor: Ocular toxoplasmosis (OT), caused by the parasite Toxoplasma gondii, is known to be a major health problem in South America, especially in Colombia and Brazil (1-3). The highest prevalence of OT has been reported in Erechim, Rio Grande do Sul, Brazil, a state that borders Uruguay and Argentina, where a representative population-based household survey showed that $17.7 \%$ of 1,042 adults examined had OT (1). For comparison, it is estimated that $\approx 2 \%$ of $T$. gondii-infected persons in the United States manifest OT (4). It is still unclear whether the high rate of OT in South America is attributable to host or parasite genetic factors or differences in exposure rate $(5,6)$.

In the province of Misiones in Argentina, the prevalence of OT in patients seeking care in an ophthalmic office is also high and has been documented as high as $20 \%$ (7). The area was mostly settled in the early 20th century by non-Hispanic European immigrants from Germany and Slavic countries who arrived through Southern Brazil.

We explored the relationship between ethnic origin and frequency of reactivation toxoplasmic retinochoroiditis (RTR) in patients who sought care in a private secondary care eye clinic in Oberá, Misiones, Argentina, during
February 2004-May 2014. All patients with uveitis were examined by a single uveitis specialist (M.R.), who performed complete ophthalmological examinations, including visual acuity, anterior biomicroscopy, tonometry, and indirect ophthalmoscopy. Study inclusion criteria were presence of RTR in 1 or both eyes and specific $T$. gondii $\mathrm{IgG}$ in blood serum samples. A minimum of 3 months with no signs of intraocular inflammation was required to differentiate chronic active retinochoroiditis from 2 consecutive episodes of RTR.

The study included 112 nonimmunosuppressed patients with RTR. The patients completed a questionnaire including demographic data for the patient, as well as the first and last names and countries of origin of parents, grandparents, and great-grandparents. Informed consent was obtained from all participants and the study was approved by the human subjects review committee of Misiones Province.

The patients were divided into 4 groups (Table): 1) patients reporting $\geq 1$ ancestor born in Spain were considered Hispanic $(\mathrm{n}=29) ; 2)$ patients without Hispanic ancestry who had $\geq 1$ ancestor born in Poland, Ukraine, Russia, or Belarus, and who spoke Polish, Ukrainian, or Russian were considered Slavic $(\mathrm{n}=28)$; 3) patients without Hispanic or Slavic ancestry who had $\geq 1$ ancestor born in Germany or the Austro-Hungarian Empire and who spoke German were considered Germanic $(\mathrm{n}=46)$; and 4) patients who did not fulfill the criteria of any of the above-mentioned groups were designated as others $(\mathrm{n}=9)$. All patients had RTR at baseline; $28 \mathrm{had} \geq 1$ more RTR episode during the followup period (Table). Multiple logistic regression analysis, in which Hispanic patients were used as a reference group, showed that Germanic and Slavic patients had a higher risk for reactivation during the follow-up period, but the odds ratio was significant only for Slavic patients after adjustment for rural dwelling.

More than $95 \%$ of Toxoplasma gondii strains in Europe belong to the clonal type II lineage, whereas strains from

\begin{tabular}{|c|c|c|c|c|}
\hline \multirow[b]{2}{*}{ Demographic and follow-up data } & \multicolumn{4}{|c|}{ Ethnicity } \\
\hline & Hispanic, $n=29$ & Slavic, $n=28$ & Germanic, $n=46$ & Other, $\mathrm{n}=9$ \\
\hline \multicolumn{5}{|l|}{ Demographic data } \\
\hline Male sex $\dagger$ & $13(44.83)$ & $14(50)$ & $20(43.48)$ & $5(55.56)$ \\
\hline Median age, y (range)† & $31(6-67)$ & $32.5(14-70)$ & $31(6-71)$ & $29(6-68)$ \\
\hline Rural dwellingt & $18(62.07)$ & $23(82.14)$ & $30(65.22)$ & $5(55.56)$ \\
\hline \multicolumn{5}{|l|}{ Follow-up } \\
\hline Length, median mo† & 37 & 42 & 38.5 & 27 \\
\hline$\geq 1$ reactivation toxoplasmic retinochoroiditis & $4(13.79)$ & $10(35.71)$ & $12(26.09)$ & $2(22.22)$ \\
\hline OR $(95 \% \mathrm{Cl})$ & Reference & $3.47(0.93-12.85) \ddagger$ & $2,2(0.63-7.65) \dagger$ & $1.78(0.27-11.86) \dagger$ \\
\hline OR adjusted for rural dwelling $(95 \% \mathrm{Cl})$ & Reference & $4.07(1.05-15.68) \S$ & $2.2(0.65-8.01) \dagger$ & $1.73(0.26-11.64) \dagger$ \\
\hline \multicolumn{5}{|c|}{ 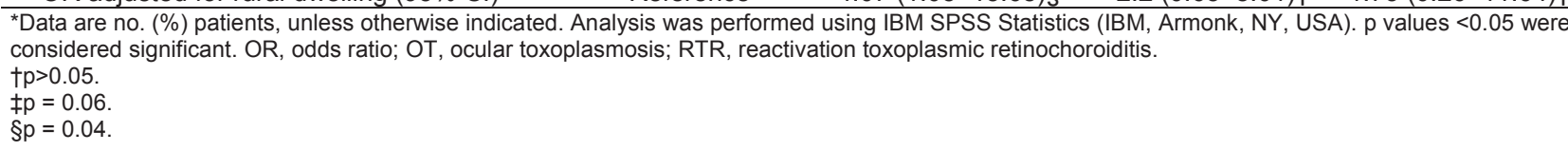 } \\
\hline
\end{tabular}


South America are genetically divergent and diverse $(6,8)$. We hypothesize that the European population is poorly adapted to South American strains and therefore more susceptible to OT. If this hypothesis is true, Native Americans who had a long history of exposure to atypical strains from South America should be more resistant to OT. This hypothesis is reinforced by a recent survey conducted among Mbyá-Guarani Indians, who had a serologic prevalence of toxoplasmosis $70 \%$, but only $3.5 \%$ of them had toxoplasmic retinochoroidal lesions (M. Rudzinski, unpub. data).

Argentineans have a large incidence of European genetic heritage in their Y-chromosomal and autosomal DNA, but $\approx 50 \%$ of their mitochondrial gene pool is of Native American ancestry (9). The amount of admixture between Europeans and Native Americans with inheritance of resistance genes to OT from Native Americans may explain the difference of susceptibility to RTR between Hispanic and non-Hispanic Europeans. Admixture events between Europeans and Native Americans mainly involved Hispanics whose migration to Argentina started in the 16th century and continued until the mid-20th century. Persons in Argentina who have Spanish surnames can carry as much as $80 \%$ Native American genetic ancestry $(9,10)$. In contrast, the Slavic and German Europeans migrated to Misiones only during a large surge of European immigration between 1890 and 1950, and did not have substantial admixture with Native Americans. Despite the fact that this study was not a random or representative sample of all ethnic groups in Argentina and the Native American mixture of the patients was not known, and environmental and dietary influences were not examined, our results suggest host genetic factors as determinants of disease severity in OT.

\section{Acknowledgments}

We thank Diaz Freitas Estela for acquisition of ancestry data.

\section{References}

1. Glasner PD, Silveira C, Kruszon-Moran D, Martins MC, Burnier Junior M, Silveira S, et al. An unusually high prevalence of ocular toxoplasmosis in southern Brazil. Am J Ophthalmol. 1992;114:136-44. http://dx.doi.org/10.1016/ S0002-9394(14)73976-5

2. de-la-Torre A, Gonzalez G, Diaz-Ramirez J, Gomez-Marin JE. Screening by ophthalmoscopy for Toxoplasma retinochoroiditis in Colombia. Am J Ophthalmol. 2007;143:354-6. http://dx.doi.org/ 10.1016/j.ajo.2006.09.048

3. Maenz M, Schluter D, Liesenfeld O, Schares G, Gross U, Pleyer U. Ocular toxoplasmosis past, present and new aspects of an old disease. Prog Retin Eye Res. 2014;39:77-106. http://dx.doi.org/ 10.1016/j.preteyeres.2013.12.005

4. Holland GN. Ocular toxoplasmosis: a global reassessment. Part I: epidemiology and course of disease. Am J Ophthalmol. 2003;136:973-88. http://dx.doi.org/10.1016/j.ajo.2003.09.040

5. Jones JL, Muccioli C, Belfort R Jr, Holland GN, Roberts JM, Silveira C. Recently acquired Toxoplasma gondii infection, Brazil. Emerg Infect Dis. 2006;12:582-7. http://dx.doi.org/10.3201/ eid1204.051081
6. Khan A, Jordan C, Muccioli C, Vallochi AL, Rizzo LV, Belfort R Jr, et al. Genetic divergence of Toxoplasma gondii strains associated with ocular toxoplasmosis, Brazil. Emerg Infect Dis. 2006;12:9429. http://dx.doi.org/10.3201/eid1206.060025

7. Rudzinski M, Meyer A. Prevalence and risk factors associated with ocular toxoplasmosis in patients from the center east region of the province of Misiones, Argentina [in Spanish]. Oftalmología Clínica y Experimental. 2011;4:159-62 [cited 2016 Feb 2]. http://www.oftalmologos.org.ar/publicaciones/OCE/volumenes/ vol4_n4/resumenes/159_prevalencia_riesgo_toxoplamosis.pdf

8. Su C, Khan A, Zhou P, Majumdar D, Ajzenberg D, Dardé ML, et al. Globally diverse Toxoplasma gondii isolates comprise six major clades originating from a small number of distinct ancestral lineages. Proc Natl Acad Sci U S A. 2012;109:5844-9. http://dx.doi.org/10.1073/pnas.1203190109

9. Corach D, Lao O, Bobillo C, van Der Gaag K, Zuniga S, Vermeulen M, et al. Inferring continental ancestry of Argentineans from autosomal, Y-chromosomal and mitochondrial DNA. Ann Hum Genet. 2010;74:65-76. http://dx.doi.org/10.1111/ j.1469-1809.2009.00556.x

10. Avena S, Via M, Ziv E, Perez-Stable EJ, Gignoux CR, Dejean C, et al. Heterogeneity in genetic admixture across different regions of Argentina. PLoS ONE. 2012;7:e34695. http://dx.doi.org/10.1371/ journal.pone. 0034695

Address for correspondence: Daniel Ajzenberg, INSERM UMR_S 1094, Neuroépidémiologie Tropicale, Laboratoire de Parasitologie-Mycologie, Faculté de Médecine, Université de Limoges, 2 rue du Docteur Marcland,87025 Limoges, France; email: ajz@unilim.fr

\section{Tropical Islands as New Hubs for Emerging Arboviruses}

\section{Van-Mai Cao-Lormeau}

Author affiliation: Institut Louis Malardé, Papeete, Tahiti, French Polynesia

DOI: http://dx.doi.org/10.3201/eid2205.150547

To the Editor: The outbreaks of dengue virus (DENV), chikungunya virus (CHIKV), and Zika virus infection that occurred on islands in the Indian Ocean, the Pacific, and the Caribbean over the past decade have demonstrated the potential of these arboviruses to pose a global public health threat. All 3 viruses were first isolated in the mid-20th century in either African or Asian countries; however, until 2005, only DENV (family Flaviviridae, genus Flavivirus) was considered a global public health concern (1).

In 2005, CHIKV infection, which typically manifests as fever, joint pain, rash, and polyarthralgia, emerged on islands in the Indian Ocean. During the next 10 years, CHIKV (family Togaviridae, genus Alphavivirus) caused several outbreaks in the Indian subcontinent, Asia, and Central Africa, and autochthonous transmission was reported in Europe (2). In 2011, CHIKV appeared for the first time in the Pacific region; 2 years later, it had expanded throughout the region (3). At the end of 2013, CHIKV 